\title{
A STUDY ON STABILIZATION OF SOIL BY ELECTRO KINETIC
} METHOD

\author{
Geeta A Megur ${ }^{1}$, P G Rakaraddi ${ }^{2}$ \\ ${ }^{I}$ Post graduate student, geotechnical engineering, Department of civil engineering, Basaveshwar Engineering College, \\ Bagalkot, Karnataka, India. \\ ${ }^{2}$ Professor, Department of civil engineering, Basaveshwar Engineering College, Bagalkot, Karnataka, India.
}

\begin{abstract}
The application of chemical ground improvement using the electro kinetic stabilization (EKS) method has the potential to overcome problems soft highly compressibility soil. This technique has the potential to enhance the strength and reduce compressibility of a wide range of soils. It is comparatively new methodology is being investigated in some parts of the world as a viable in situ soil remediation and treatment method. The principles of EK treatment method involve applying a low direct current or a low potential gradient to electrodes inserted in the low permeable soils that cannot readily drained. The aim of this study was to evaluate the use of EKS as an effective method to strengthen soft clayey soil. The investigations were carried out in the laboratory using locally collected Red soil is used as it possess different mineralogy and geotechnical properties. The chemical substances used as electrolytes in the experiments were sodium silicate $(\mathrm{Na})$, calcium chloride $(\mathrm{Ca})$ in addition to distilled water $(\mathrm{DW})$, The combined effect of these processes together with various geochemical reactions alters the chemical composition of the soil porous medium and thereby alters the physicochemical properties of the soil. Three different anode and cathode electro kinetic systems were employed in this study, namely $D W-D W, N a-D W$ and Ca-DW, under voltage gradients of $30 \mathrm{~V}$ for periods of 3, 7, and 14 days. After electro kinetic processing, soil was tested for shear strength test. The experimental results suggest the potential of developing electro kinetic treatment technique to stabilize shear strength of expansive soils effectively and efficiently.
\end{abstract}

Keywords: Electro kinetic stabilization; chemical injection; clayey soil; shear strength $* * *$

\section{INTRODUCTION}

In recent years, major settling or tilting of buildings and bridges, instability of dams and road embankments have been observed and many attempts have been made in order to mitigate such damages. The behavior of expansive soils is uncertain when subjected to moisture changes. The strength properties of these soils change according to the amount of water contained in the voids of the soils. The movement of water into and out of the soil voids induces severe swell shrink behavior causing stress levels which could result to damages to facilities placed on them. Highway facilities in particular stretch over considerable distances traversing diverse soil formations. The chances of encountering expansive soils are therefore high with highway facilities. Expansive soil behavior is generally attributed to clay soils, and is characterized by excessive compression, dispersive behavior, collapsing behavior, low shear strength, high swell potential, and frost susceptibility. They are therefore not suitable for use without improvement of their properties.

For many years, civil engineers are faced with a great challenge to design structures on soft compressible soils which include soft clay, silt and peat foundations. Consolidation of water-saturated, fine-grained soil occurs very slowly because the low permeability of these soils impedes the escape of pore water from the soil voids. Such soils have poor drainage and strength properties. Even under large temporary surcharge loads, settlement can take years because of this slow water movement and the great distance the water must move to exit the soil.

To increase the soil stability based on the requirement of economic cost, there are few numerous methods of soil improvement methods according to the geological conditions, soil types and environments may be implemented.

In this regard, it is necessary to determine the soil improvement alternatives, technically and economically, from the ultimate state design in accordance with geotechnical categories, to stabilize and remediate the existing soft problematic soils prior to the commencement of any construction activities. The aims of improving soils (as foundation and construction materials) are to increase strength, reduce distortion under stress, reduce compressibility, control shrinking and swelling, control permeability and reduce water pressure (redirect seepage), prevent detrimental physical or chemical changes due to environmental conditions, reduce susceptibility to liquefaction, reduce natural variability of borrow materials and etc. 
Conventional remediation methods have been known successful in minimizing several damages, however, they are expensive, time-consuming and may be difficult to implement in some existing structures [1]. In this regard, electrochemical or electrokinetic (EK) treatment method can be used as an alternative soil treatment method for remediation of those deficiencies underneath building foundations, roads, railways or pipelines. The use of this technique involves an approach with minimum disturbance to the surface while treating subsurface contaminants and improving the engineering characteristics of subsurface soils [2].

The use of EK treatment which is a comparatively new methodology is being investigated in some parts of the world for the potential application through several laboratory experiments to verify the versatility and effectiveness of this technique in practice as a viable in-situ soil remediation and treatment method [3].

In the present investigation attempt has been made to stabilize Red soil by electro kinetic method of using different chemicals. The soil is collected from Vidyagiri, Bagalkot, Karnataka state. The Sodium silicate and Calcium chloride were used in the present study and are mixed with Red soil to investigate the relative change in the strength. A series of unconfined compression strength tests were carried out on soil samples with chemical concentration of $1 \mathrm{~mol} / \mathrm{lit}, 1.5 \mathrm{~mol} / \mathrm{lit}$. The test results show that reinforcement of polypropylene fibers leads to an improvement of the shear strength of soil.

\section{BACKGROUND}

Many researchers presented different theories of electrokinetic treatement using different chemicals and different soils. Depending on their experimental results, sodium silicate and calcium chloride is commonly used and has been used for this study also. Saiful Azhar Ahmad Tajudin (2012): This study was conducted in two stages using laboratory scale models, using an inactive kaolinite clay. The test model using reusable Electrokinetic Geosythentics (EKG) developed to apply a constant voltage gradient of $50 \mathrm{~V} / \mathrm{m}$ across a soil sample approximately $400 \mathrm{~mm}$. The first stage involved testing of a 'pure' system with distilled water as the main pore electrolyte fluid supplied under zero hydraulic gradient conditions for periods of 3, 7 and 14 days. The second stage repeated test using calcium chloride and distilled water, DW and sodium silicate and, at the anode and cathode, respectively. Throughout both physical and chemical characteristics were measured. Hossein Moayedi et al. (2011):This paper discusses the utility of polyvinyl alcohol (PVA) as polymeric binders in soft clays. The effects of added polymers on unconfined compressive strength, UCS, are reported. This reported research involved a number of experiments using cement, sodium silicate and two types of PVA to stabilize kaolinite as soft clay, in order to provide a better understanding of the strength behavior of kaolinite after stabilization with various dosages of PVA. Mosavat et al., (2013):He conducted the experiments using stainless steel electrodes under total applied voltage of $30 \mathrm{~V}$ for period of 15 days. Two types of finegrained soils, kaolinite and bentonite, were used as they possess different mineralogy and geotechnical properties. Kamarudin Ahmad et al. (2006) In this study the chemical substances used as electrolytes were aluminum chloride ( $\mathrm{Al})$, calcium chloride $(\mathrm{Ca})$ and phosphoric acid (PA) in addition to distilled water (DW). Four different opened-anode and opened-cathode electrokinetic systems were employed in this study, namely DW-DW, Al-DW, Ca-DW and DW-PA. A constant voltage of $30 \mathrm{~V}$ was applied for 168 hours to each of the opened-anode and opened-cathode configuration system. It was observed that the quantities and directions of electro osmotic flows were dependent upon the types of electrolyte. Waddah S. Abdullah et al. (2011): In this study the medium expansive soil specimens were mixed with various percentages of cement contents $(1 \%, 2 \%, 3 \%$ and $4 \%)$ and molded to a range of prescribed pre-wetting dry densities and moisture contents. It was found that $2 \%$ cement content cured for 28 days was sufficient to reduce the free swell percentage for medium expansive soil from as high as $7.4 \%$ to merely $0.4 \%$. The potential swell pressure, however, was reduced from a damagingly high value $(333 \mathrm{kPa})$ for the untreated soil to a tolerable value $(20 \mathrm{kPa})$ for the same enhancement conditions.

\section{MATERIALS AND EXPERIMENTAL STUDY}

The testing is carried out on Red soil and is mixed with different percentage of chemical content to know the change in strength.

\subsection{Red Soil}

The Red soil is collected from vidyagiri Bagalkot, Karnataka. At the time of collection of sample sufficient care has been taken to avoid the mixing of unwanted materials like wastes, roots and minerals. The soil is collected at a depth of $1 \mathrm{~m}$ from ground level at the sites and was air dried and pulverized in a ball mill after separating the pebbles. The pulverized soil which is passing through $4.75 \mathrm{~mm}$ IS sieve was used in the present investigation. The physical and chemical properties of the collected soils were studied by conducting various laboratory tests conforming to Indian Standard codes. The basic and index properties of the soil are determined from laboratory experiments according to IS Code 2720 Part IV (1985) of practices. The tests conducted on Red soils are specific gravity test, liquid limit test, plastic limit test, swell index test, compaction test, consolidation, unconfined compression test, $\mathrm{PH}$, Electrical conductivity test as per IS 2720 part III/Sec-1 (1980), IS 2720 part V (1985), IS 2720 part VII \& VIII (1974) and IS 2720 part XI respectively. 
The physical and chemical properties of Red soil before test are

Table 1: The physical and chemical properties of Red soil

\begin{tabular}{|c|c|c|}
\hline $\begin{array}{c}\text { Sl. } \\
\text { No }\end{array}$ & \multicolumn{1}{|c|}{ Properties } & Value \\
\hline 1 & Colour & Red \\
\hline 2 & Specific Gravity(G) & 2.58 \\
\hline 3 & Liquid limit, $\mathrm{w}_{\mathrm{L}}(\%)$ & $28 \%$ \\
\hline 4 & Plastic limit, $\mathrm{w}_{\mathrm{P}}(\%)$ & $17.59 \%$ \\
\hline 5 & Shrinkage limit & $13.023 \%$ \\
\hline 6 & $\begin{array}{c}\text { Maximum dry density, } M D D \\
\left(\mathrm{~g} / \mathrm{cm}^{3}\right)\end{array}$ & 1.73 \\
\hline 7 & $\begin{array}{l}\text { Permeability test by constant } \\
\text { head method }\end{array}$ & $2.547 \times 10^{3} \mathrm{~cm} / \mathrm{sec}$ \\
\hline 8 & $\begin{array}{l}\text { Permeability test by falling } \\
\text { head method }\end{array}$ & $1.82 \times 10^{3} \mathrm{~cm} / \mathrm{sec}$ \\
\hline 8 & PH & 6.19 \\
\hline 9 & Electrical conductivity & $667.69 \mu \mathrm{mho} / \mathrm{cm}$ \\
\hline
\end{tabular}

\subsection{Chemical Stabilizers Sodium Silicate and Calcium}

\section{Chloride}

There are several criteria for the selection of chemical stabilizers used in this study:

(a) Significant improvements of the properties of soils after treatment are expected to be seen.

(b) Stabilizers are soluble in water so can be transported by electric current.

(c) They are inexpensive.

(d) They are environmentally safe.

Based on these criteria and the work of previous researchers in bench studies (see Rogers et al., 2002), the chemical stabilizers selected for this study are calcium chloride $\left(\mathrm{CaCl}_{2}\right)$ and sodium silicate $\left(\mathrm{Na}_{2} \mathrm{SiO}_{3}\right)$ at various concentrations 1 , $1.5 \mathrm{~mol} / \mathrm{liter}$. These were place at either anode or cathode, and efficiency evaluated.

\subsection{Electrode}

In order to eliminate the complexity within the test system, stainless steel electrodes are used.

\subsection{Experimental Setup}

The set up consists of a rectangular glass of size (300mmx200mmx300mm), 30V-60V power pack to supply the voltage and stainless steel electrodes. Soil is mixed with water and is compacted in 3 layers to achieve the same density of nature soil and trying to avoid leaving cavities in the specimen. Coir was used at both perforated sides of wall and from inside the main compartment to prevent soil particle movement into the electrode chambers. The soil is consolidated by supplying water through the holes and the load was applied to consolidate the slurry sample. After consolidation the hollow circular stainless steel electrodes are immersed and a constant electric potential of $30 \mathrm{~V}$ was applied across it for a fixed period of time. The chemicals sodium silicate and calcium chloride at different concentration of 0,1 , $1.5 \mathrm{~mol} / \mathrm{liter}$ is poured at anode and cathode respectively. At the end of the trial, the soil specimen was removed from the test setup and the UCS test is carried out at 3, 7 and 14days to compare the strength.

Table 2: Codes for EK treatment systems Code

\begin{tabular}{|l|l|l|}
\hline Codes & Anolyte & Catholyte \\
\hline $\begin{array}{l}\text { DW-DW } \\
\text { (pure } \\
\text { system) }\end{array}$ & $\begin{array}{l}\text { Distilled } \\
\text { water }\end{array}$ & Distilled water \\
\hline Ns-Ca & $\begin{array}{l}1.0 \mathrm{M} \text { sodium } \\
\text { silicate }\end{array}$ & $\begin{array}{l}1.0 \mathrm{M} \text { calcium } \\
\text { chloride }\end{array}$ \\
\hline Ns-Ca & $\begin{array}{l}1.5 \mathrm{M} \text { sodium } \\
\text { silicate }\end{array}$ & $\begin{array}{l}1.5 \mathrm{M} \text { calcium } \\
\text { chloride }\end{array}$ \\
\hline
\end{tabular}

In pure system electro kinetic stabilization method, Distilled water was used as electrolytes in that were filled in electrode chambers and subject to electric current for 3, 7, and 14 days.

Electro kinetic testing was designed to study the effect of electro kinetic mechanisms that contribute the increase of soil shear strength in electrochemical process by transportation of cat ions and anions at anode and cathode, respectively by combining the chemical stabilizers. The test was conducted by feeding calcium chloride and sodium silicate at the anode and cathode respectively to know the effects of cat ion and anion of species into the system.

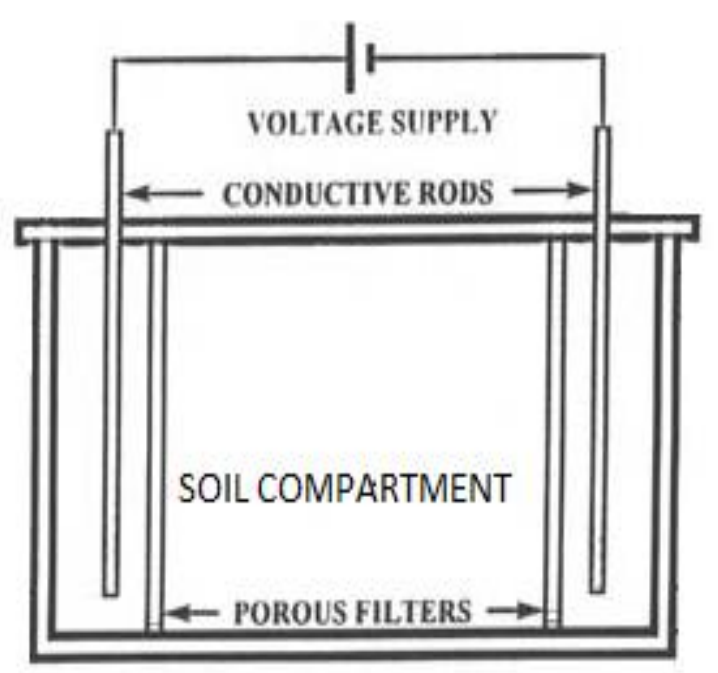

Fig-1: Line diagram of Experimental Setup 


\section{RESULTS AND DISSCUSION}

\subsection{Unconfined Compression Test (UCS)}

UCS test results for three day consolidation at 5 and $15 \mathrm{~cm}$ distance from the anode are presented in figures 2 and 3. In figure 4-5 and 6-7 seven day and fourteen days consolidation at 5 and $15 \mathrm{~cm}$ spacing from anode is shown. The increasing the UCS values are observed for various concentrations of sodium silicate and calcium chloride dosage.

1. After a period of three days, the UCS results for $5 \mathrm{~cm}$ and $15 \mathrm{~cm}$ distance from anode were (i) $0.325 \mathrm{~kg} / \mathrm{cm}^{2}$, $0.335 \mathrm{~kg} / \mathrm{cm}^{2}$ and $0.46 \mathrm{~kg} / \mathrm{cm}^{2}$ (ii) $0.335 \mathrm{~kg} / \mathrm{cm}^{2}$, $0.345 \mathrm{~kg} / \mathrm{cm}^{2}$ and $0.467 \mathrm{~kg} / \mathrm{cm}^{2}$ at a concentration of 0 , 1 , and $1.5 \mathrm{~mol} /$ lit respectively.

2. At a concentration of $0 \mathrm{~mol} / \mathrm{lit}, 1 \mathrm{~mol} / \mathrm{lit}$ and $1.5 \mathrm{~mol} / \mathrm{lit}$ the UCS strength after seven days consolidation for $5 \mathrm{~cm}$ and $15 \mathrm{~cm}$ distance from anode were $0.41 \mathrm{~kg} / \mathrm{cm}^{2}$, $0.425 \mathrm{~kg} / \mathrm{cm}^{2}$ and $0.725 \mathrm{~kg} / \mathrm{cm}^{2}$, and $0.37 \mathrm{~kg} / \mathrm{cm}^{2}$, $0.395 \mathrm{~kg} / \mathrm{cm}^{2}$ and $0.755 \mathrm{~kg} / \mathrm{cm}^{2}$ respectively.

3. The fourteen days UCS test results for 5 and $15 \mathrm{~cm}$ distance were (i) $0.33 \mathrm{~kg} / \mathrm{cm}^{2}, \quad 0.445 \mathrm{~kg} / \mathrm{cm}^{2}$ and $0.775 \mathrm{~kg} / \mathrm{cm}^{2}, \quad$ (ii) $0.435 \mathrm{~kg} / \mathrm{cm}^{2}, \quad 0.46 \mathrm{~kg} / \mathrm{cm}^{2}$ and $0.795 \mathrm{~kg} / \mathrm{cm}^{2}$ respectively for a concentration of 0,1 , and $1.5 \mathrm{~mol} / \mathrm{lit}$.

4. The soil shows the brittle behavior as the concentration of the chemical is at $1.5 \mathrm{~mol} / \mathrm{lt}$. The UCS is more at lower strain.

The values of UCS for different concentration, consolidation period and distance from anode are given in Table 3.

Table 3: UCS test results at 3, 7 and 14 days at various concentrations.

\begin{tabular}{|l|l|l|l|l|}
\hline $\begin{array}{l}\text { Chemical } \\
\text { concen- } \\
\text { Tration }\end{array}$ & $\begin{array}{l}\text { Dist } \\
\text { from the } \\
\text { anode }\end{array}$ & $\begin{array}{l}3 \\
\text { days }\end{array}$ & $\begin{array}{l}7 \\
\text { days }\end{array}$ & $\begin{array}{l}14 \\
\text { days }\end{array}$ \\
\hline $0 \mathrm{~mol} / \mathrm{lit}$ & $\begin{array}{l}\text { At 5cm } \\
\text { dist }\end{array}$ & 0.325 & 0.410 & 0.330 \\
\cline { 2 - 5 } & $\begin{array}{l}\text { At } 15 \mathrm{~cm} \\
\text { dist }\end{array}$ & 0.335 & 0.370 & 0.435 \\
\hline $1 \mathrm{~mol} / \mathrm{lit}$ & $\begin{array}{l}\text { At } 5 \mathrm{~cm} \\
\text { dist }\end{array}$ & 0.335 & 0.425 & 0.445 \\
\cline { 2 - 5 } & $\begin{array}{l}\text { At } 15 \mathrm{~cm} \\
\text { dist }\end{array}$ & 0.345 & 0.395 & 0.460 \\
\hline $\begin{array}{l}1.5 \\
\mathrm{~mol} / \mathrm{lit}\end{array}$ & $\begin{array}{l}\text { At } 5 \mathrm{~cm} \\
\text { dist }\end{array}$ & 0.460 & 0.725 & 0.775 \\
\cline { 2 - 5 } & $\begin{array}{l}\text { At } 15 \mathrm{~cm} \\
\text { dist }\end{array}$ & 0.467 & 0.755 & 0.795 \\
\hline
\end{tabular}

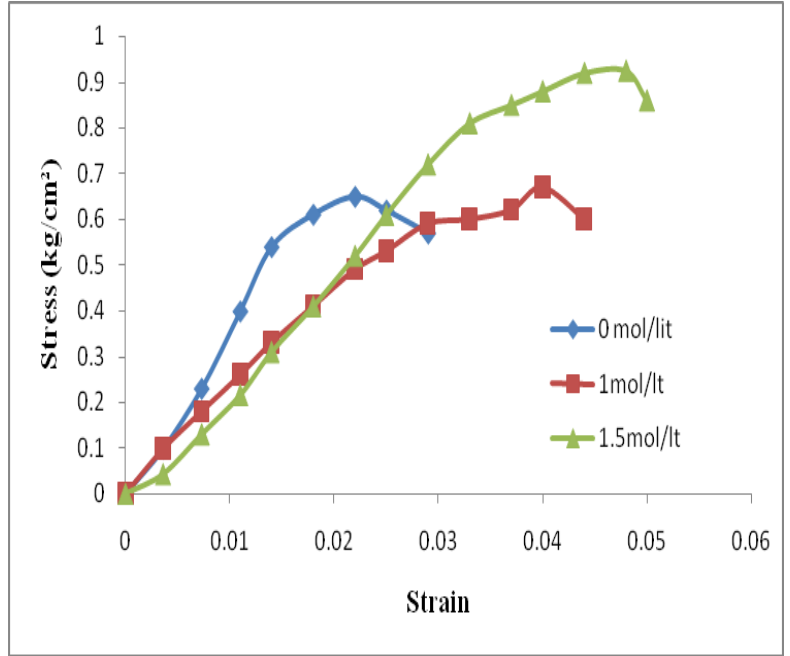

Fig- 2: UCS 3days test results at $5 \mathrm{~cm}$ distance from the anode.

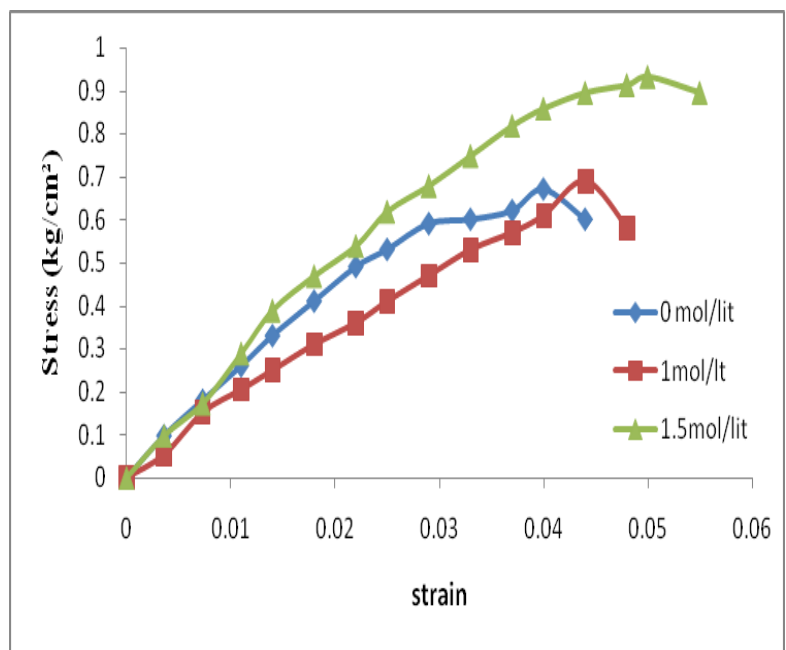

Fig- 3: UCS 3days test results at $15 \mathrm{~cm}$ distance from the anode.

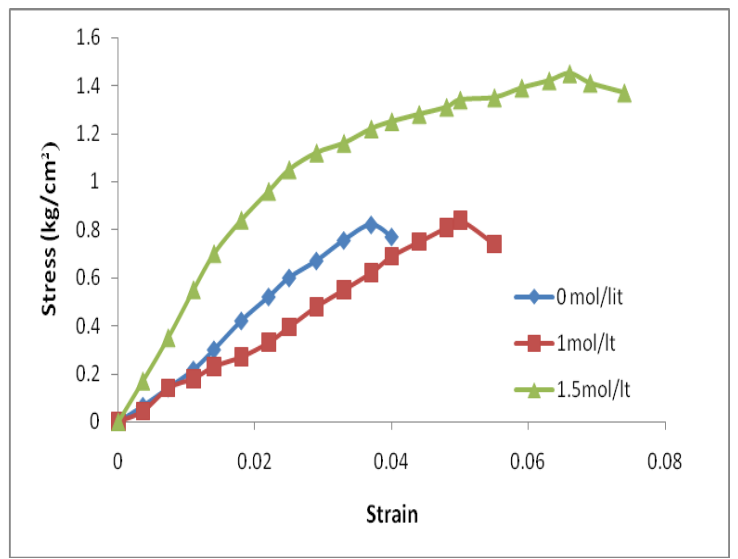

Fig-4: UCS 7days test results at $5 \mathrm{~cm}$ distance from the anode. 


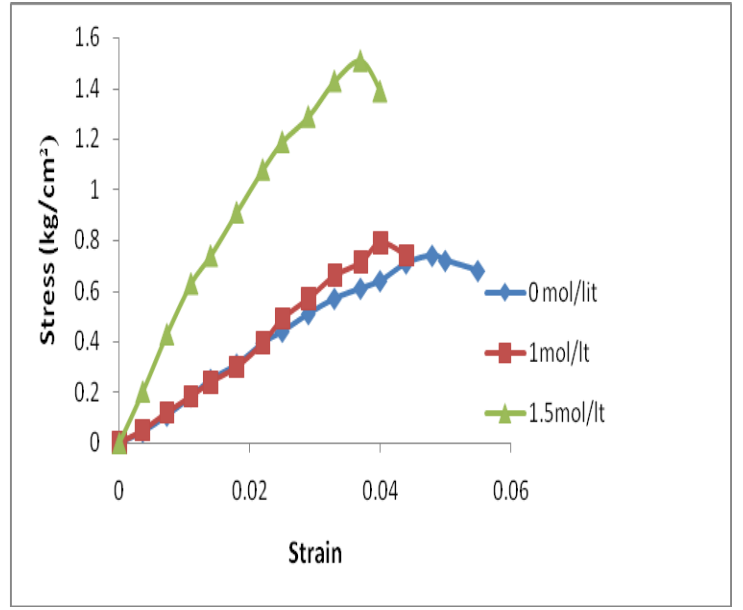

Fig- 5: UCS 7 days test results at $15 \mathrm{~cm}$ distance from the anode.

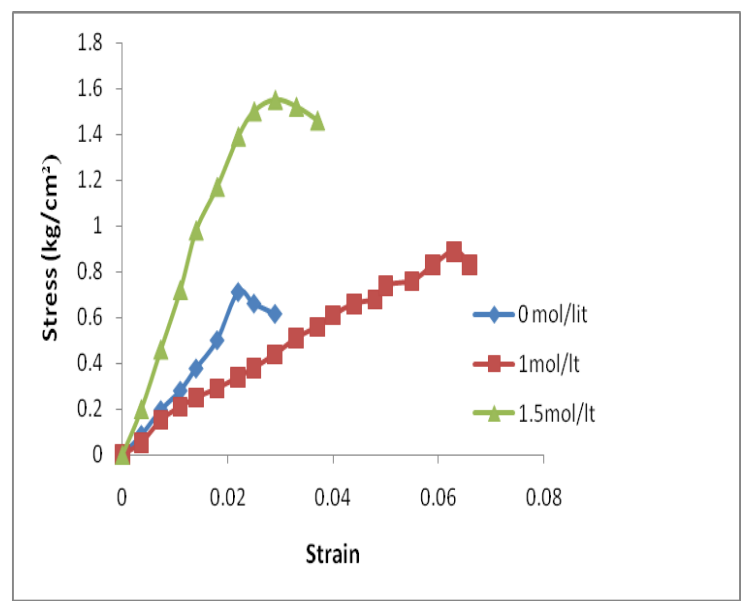

Fig- 6: UCS 14 days tests results at $5 \mathrm{~cm}$ distance from the anode.

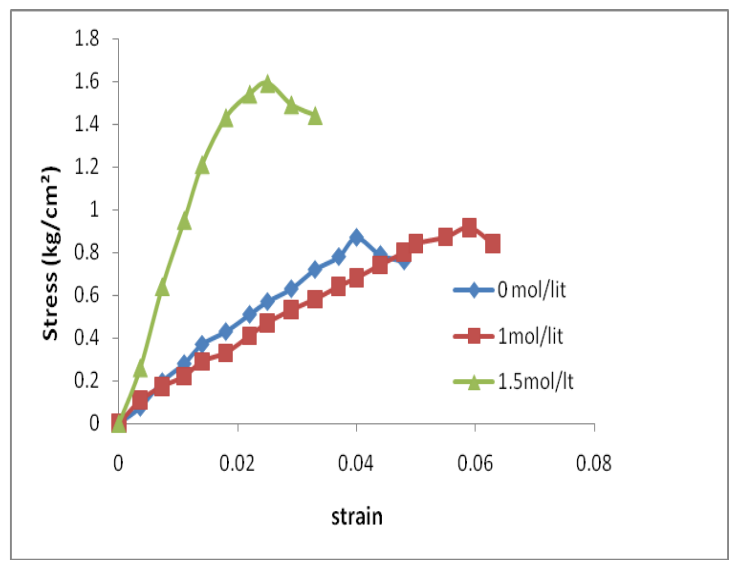

Fig- 7: UCS 14 days tests results at $15 \mathrm{~cm}$ distance from the anode.
5. The maximum stress obtained is $0.795 \mathrm{~kg} / \mathrm{cm}^{2}$ at $1.5 \mathrm{~mol} /$ lit concentration of sodium silicate and calcium chloride. This is due to hydration process of cement content which could make a better bonding along with time. Besides, this could probably because of available silicate minerals in clay portion of the kaolinite[3].

6. The net electro osmotic flow in red soil for pure system, sodium silicate-calcium chloride for different concentration systems was towards the cathode. This was due to positive sign of zeta potential during EK processing

\section{CONCLUSIONS:}

From the experimental results of the UCS tests with addition of sodium silicate and calcium chloride content, the unconfined strength increases with an increase in the content on the chemical. This study confirmed possible migration of silicate and calcium ions in soil leads to stabilization of soil. Addition of chemicals shows an increase in the consolidation rate and unconfined sompressive strength. The Cohesion value increases considerably at 14 days as compared to the 3 and 7 days test results.

\section{REFERANCES:}

[1] Kamarudin Ahmad(2006). Malaysian Journal of Civil Engineering 18(2) : 74-88, electroosmotic flows and electromigrations during electrokinetic processing of tropical residual soil.

[2] Hossein Moayedi1,*, Afshin Asadi 2 , Fatemeh Moayedi3, Bujang B K Huat 1, Lim Wee Chea1(2011). International Journal Of ELECTROCHEMICAL SCIENCE Optimizin Stabilizers Enhanced Electrokinetic Environment to Improve Physicochemical Properties of Highly Organic Soil.

[3] Saiful azhar ahmad tajudin(2012). Electrokinetic Stabilisation of soft clay Published in University of Bhirmingham.

[4] Nader Shariatmadari, Amin Falamaki(2007). Electrokinetic removal of phenol and petroleum hydrocarbons from contaminated clays.

[5] Mary M. Page1 and Christopher L. Page2 (2002). Electroremediation of Contaminated Soils.

[6] Waddah S. Abdullah and Ahmed S. Alsharqi (2011) Jordan Journal of Civil Engineering, Volume 5, No. 3. Rehabilitation of Medium Expansive Soil Using Cement Treatment.

[7] Nasim Mosavat et al., Int. J. of GEOMATE, June, 2012, Vol. 2, No. 2. A Review of Electrokinetic Treatment Technique for Improving the Engineering Characteristics of Low Permeable Problematic Soils.

[8] Soon-Oh Kim, Kyoung-Woong Kim(2011), Journal of Hazardous Materials B85 195-211. Monitoring of electrokinetic removal of heavy metals in tailing-soils using sequential extraction analysis. 
[9] Krishna R. Reddy(2002) Indian Geotechnical Journal, 32 (2), Effects of Soil Moisture and Heavy Metal Concentrations on Electrokinetic Remediation.

[10] L. S. Thakur et al., (2011) Indian Geotechnical Conference, Kochi (Paper No.H-211). Strengthening silty soil using electrokinetic grouting.

[11] Hashim Mohammed Alhassan et al., (2013)British Journal of Applied Science \& Technology 3(3): 406416, Effect of 'Ionic Soil Stabilizer 2500'on the Properties of Black Cotton Soil.

[12] Nasim Mosavat et al (2013), Laboratory Assessment of Kaolinite and Bentonite under Chemical electrokinetic treatment.

[13] Hossein Moayediet al.,(2011), International Journal of Electrochem science 6, Electrophoresis of Suspended Kaolinite in Multivalent Electrolyte Solution.

[14] Hossein Moayediet al,.(2011) Int. J. Electrochem. Sci.,6 2526 - 2540 Enhancing Electrokinetic Environment to Improve Physicochemical Properties of Kaolinite Using Polyvinyl Alcohol and Cement Stabilizers.

\section{BIOGRAPHIES}

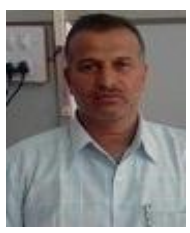

Dr P G Rakaraddi, He is presently working as a Associate professor in Basaveshwar Engineering College Bagalkot, Karnataka. He had finished his post graduate in geotechnical engineering IIT kanakpur. And also he got Phd in soil dynamics from IISc Bangalore.

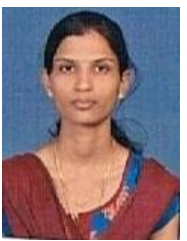

Geeta A Megur, Student of Mtech in Goetechnical engineering at BEC Bagalkot, Karnataka 